\title{
Experimental setup for flow and sediment flux characterization at desanding facilities
}

\author{
C. Paschmann*, J.N. Fernandes, D.F. Vetsch, R.M. Boes \\ Laboratory of Hydraulics, Hydrology and Glaciology (VAW), ETH Zurich, Zurich, Switzerland
}

\section{A R T I C L E I N F O}

\section{Keywords:}

Desanding facility

Sediment trapping efficiency

Prototype measurement campaign

$3 \mathrm{D}$ flow velocities

Suspended sediment concentration

Particle size distribution

\begin{abstract}
A B S T R A C T
Desanding facilities are located between the water intake and the penstock of medium and high-head hydroelectric power plants to avoid the entrance of suspended sediments into the penstock and therefore to reduce hydro-abrasion at turbine parts. This paper focusses on the selection and description of measurement instrumentation to characterize flow and sediment flux at desanding facilities with high spatial and temporal resolution. The selection criteria for the instrumentation are highlighted and the capabilities and limitations of the devices and techniques are described. The modular design of mounting system carrying the instrumentation allows for measurement under several structural constraints. The chosen concept for data acquisition in terms of measurement grid, measurement duration and sampling frequency provides high resolution data of flow quantities and sediment flux. For reliable quantification of sediment fluxes, in-line measurements of turbidity are correlated with suspended sediment concentration obtained by water sampling, also considering density and temperature. Selected findings from the field measurement campaign at two sites in Switzerland are presented and discussed. The employed experimental setup proved to be appropriate and reliable to characterize the flow field and sediment fluxes in desanding facilities at high resolutions.
\end{abstract}

\section{Introduction}

The presence of suspended sediments in the turbine water of hydroelectric power plants (HPPs), particularly with medium and high-heads, can entail operational and financial drawbacks due to possible hydro-abrasion at turbine parts [1]. To counter these problems, desanding facilities are typically located between the water intake and the headwater way leading to the turbines in the power house. Desanding facilities aim at reducing the sediment mass as well as the average particle size in the turbine water. For this purpose, sediment-laden water is diverted via an inlet channel into a basin with larger flow area. As a consequence, the flow velocity is reduced, allowing the suspended sediments to settle within the basin. The 'clear' water is then conveyed to the headwater way. The deposited sediments are either continually or intermittently flushed out of the facility and discharged back to the river. A typical design of a desanding facility is schematically shown in Fig. 1. It may include an inlet channel, a transition zone (typically with a divergent channel) and a settling basin.

Various investigations at alpine desanding facilities (e.g [2].) revealed unsatisfactory flow conditions and low particle trapping efficiencies, although the investigated facilities meet current design recommendations as described e.g. by $[3,4]$. Since the trapping efficiency of desanding facilities is directly related to hydro-abrasion in the turbines, the facility performance represents a key factor for sustainable and economic operation of HPPs.

Within the scope of a research project at the Laboratory of Hydraulics, Hydrology and Glaciology (VAW) of ETH Zurich, enhanced design guidelines for desanding facilities shall be developed based on a composite approach, combining numerical simulations and precedent field measurements. For this purpose, it was aimed at obtaining high quality flow field and sediment flux measurement data in a dense measurement grid and at high temporal resolution from desanding facility prototypes. The facilities Saas Balen and Wysswasser (both located in canton Valais, Switzerland) were selected for this investigation.

The present paper describes the measurement instrumentation, the specific measuring methods and specifications as well as the composition of the modular and flexible setup for the field measurements. Moreover, the paper delineates the experiences gained with this novel combination of various instrumentation used to monitor flow and sediment characteristics with high temporal and spatial resolutions in desanding facilities. The measurement setup was designed to record 3D flow velocities as well as sedimentological parameters. The latter comprise turbidity, density and temperature of the water-sediment

\footnotetext{
* Corresponding author.

E-mail address: paschmann@vaw.baug.ethz.ch (C. Paschmann).
} 


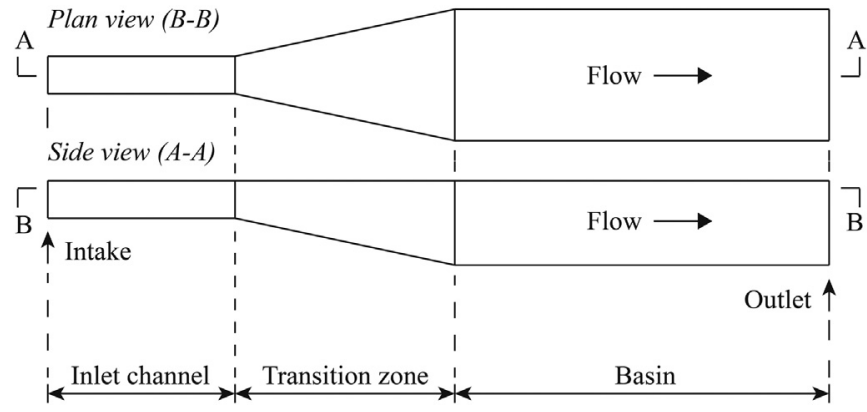

Fig. 1. Schematic illustration of a typical desanding facility geometry.

mixture. Furthermore, numerous water samples were taken to determine the suspended sediment concentration (SSC) and particle size distribution (PSD) in the laboratory. The main results obtained within the measuring campaign are presented in order to provide information regarding the applicability and consistency of the measurement setup.

\section{Measurement concept}

Desanding facilities are typically composed of (i) an intake structure, (ii) an inlet channel diverting the water towards the basin, (iii) a transition zone with continuous increase of flow area and (iv) a basin along with (v) an outlet structure at the end. For the description of the flow and the sediment fluxes in these facilities, the measurement concept was developed to obtain high-resolution measurement data of flow velocity, turbidity, density and temperature of the water-sediment mixture in a dense measurement grid throughout the basin, as well as supplementary measurements of flow velocity and turbidity in the inlet and in the outlet areas. The density measurements allow for correlating density and SSC especially at higher SSC values to supplement the correlation of turbidity and SSC. Beside those direct measurement techniques, numerous water samples were taken to determine (i) the SSC by weighing the dried residue and (ii) the PSD by using a laser particle size analyzer in the laboratory. This is a common procedure to find a correlation between measured turbidity and SSC as well as to determine the PSD.

The applied measurement instrumentation comprises (i) acoustic Doppler velocimeters (ADV), (ii) turbidity sensors, (iii) radar sensor, (iv) Coriolis flow- and density meter (CFDM) and (v) automatic bottle sampler. The devices are shown in Fig. 2 and the technical specifications are subsequently described in detail. The names of the devices and manufacturers are mentioned for information purposes only.

\section{Instrumentation}

\subsection{Acoustic Doppler velocimeters}

Nortek Vectrino+ ADVs with side-looking head and flexible cable stem were used for the 3D flow velocity measurements. The maximum frequency is $200 \mathrm{~Hz}$ and the nominal measurement accuracy is \pm $0.001 \mathrm{~m} / \mathrm{s} \pm 0.005$ times the measured velocity components.

The ADV measuring principle is based on the Doppler effect. The (stationary) ADV probes emit a signal of known frequency which is partly reflected by particles passively transported in the flowing water. Consequently, the flow velocity is computed based on the recorded frequency shift between the emitted and the received signal [5]. It is therefore assumed that particles and water have the same velocities. To obtain spatial velocity information, the instrument has one beam for each velocity component and an additional fourth beam (not used with side-looking probe design) for an independent measurement of the vertical flow velocity component. The signals are internally processed and combined by taking the probe orientation in the water into account.
Restrictions can occur when no particles are present in the flow, or at very high suspended sediment concentrations. In the former case, the signal cannot be reflected, whereas in the latter case the overall signal absorption at the particle surfaces is too high, leading to no signal reflection.

In view of the range of application, ADV measurements are reported to be very suitable for velocity measurements in free surface flows [6], showing the same level of accuracy regarding the determination of mean flow velocities as laser Doppler velocimetry, ascertained based on laboratory investigations $[7,8]$. express the possibility to measure turbulence and capture the major fraction of the turbulent kinetic energy (TKE) due to the high temporal resolution of ADV measurements. This was validated by investigations of [9].

The employed ADV probe model was on the one hand selected based on laboratory experiences, in-house expertise and availability. On the other hand, laboratory investigations of [10] comparing three different ADV systems found the Nortek Vectrino to perform very reliably under various conditions. The noise level, the response to device tilting as well as the disturbance onto the flow field was lowest, whereas the signal-to-noise ratio (SNR) as a measure of quality was consistently highest for the investigated cases.

The capability of performing measurements in turbid water due to the lower deterioration of the acoustic compared to the optical transmission [7] is advantageous for the application of ADVs in desanding facilities [2]. presents the general capability to conduct high-quality ADV measurements at alpine desanding facilities by means of a measurement campaign realized at prototype scale.

\subsection{Turbidity sensors}

Turbidity sensors CUS52D of Endress+Hauser have been used for real-time and continuous water turbidity measurements. The measuring principle of these optical sensors is based on $90^{\circ}$ light scattering, which is more sensitive than other measuring principles to a variation of particle characteristics like size and shape [11]. The nominal measurement accuracy is $2 \% \pm 0.01 \mathrm{FNU}$ (Formazine Nephelometric Units). Using similar optical backscatter devices, investigations of e.g [11-13]. indicate a reliable use in the measurement of SSCs up to several $\mathrm{g} / \mathrm{l}$.

In an overview summarizing numerous techniques regarding SSC measurements [14], mention the approximately linear correlation between optical backscatter and SSC at constant conditions, and the high temporal measurement resolution as advantages of such sensors. In contrast, the dependency on particle color, shape and especially size of the suspended sediments [11] is disadvantageous for the correlation between turbidity and SSC in natural waters.

Based on a field study [15], demonstrate the influence of particle shape on optical turbidity measurements. Although showing almost the same mass-related median diameter at the testing conditions, flaky mica particles induce around four times higher turbidity readings than glass spheres.

Following [16], optical turbidity sensor readings are greatly affected by changes in particle sizes below $100 \mu \mathrm{m}$, but minimally affected in a particle size range of $200-400 \mu \mathrm{m}$. Similar results were obtained by laboratory investigations of [11]. For synthesized water-sediment suspensions with identical SSC composed of different sands $\left(d_{50}=107-430 \mu \mathrm{m}\right)$, silt and clay $\left(d_{50}=40 \mu \mathrm{m}\right)$, the response of the examined optical turbidity sensors increased considerably with increasing proportion of silt and clay in the suspension.

Conducting measurements at constant discharge conditions and permissibly assuming virtually constant particle shapes and colors in the catchment area and similar size distributions in the flow during the measuring campaign, the previously mentioned constraints can be minimized. In order to safeguard turbidity measurements, particle size analyses should be conducted in addition [16]. 


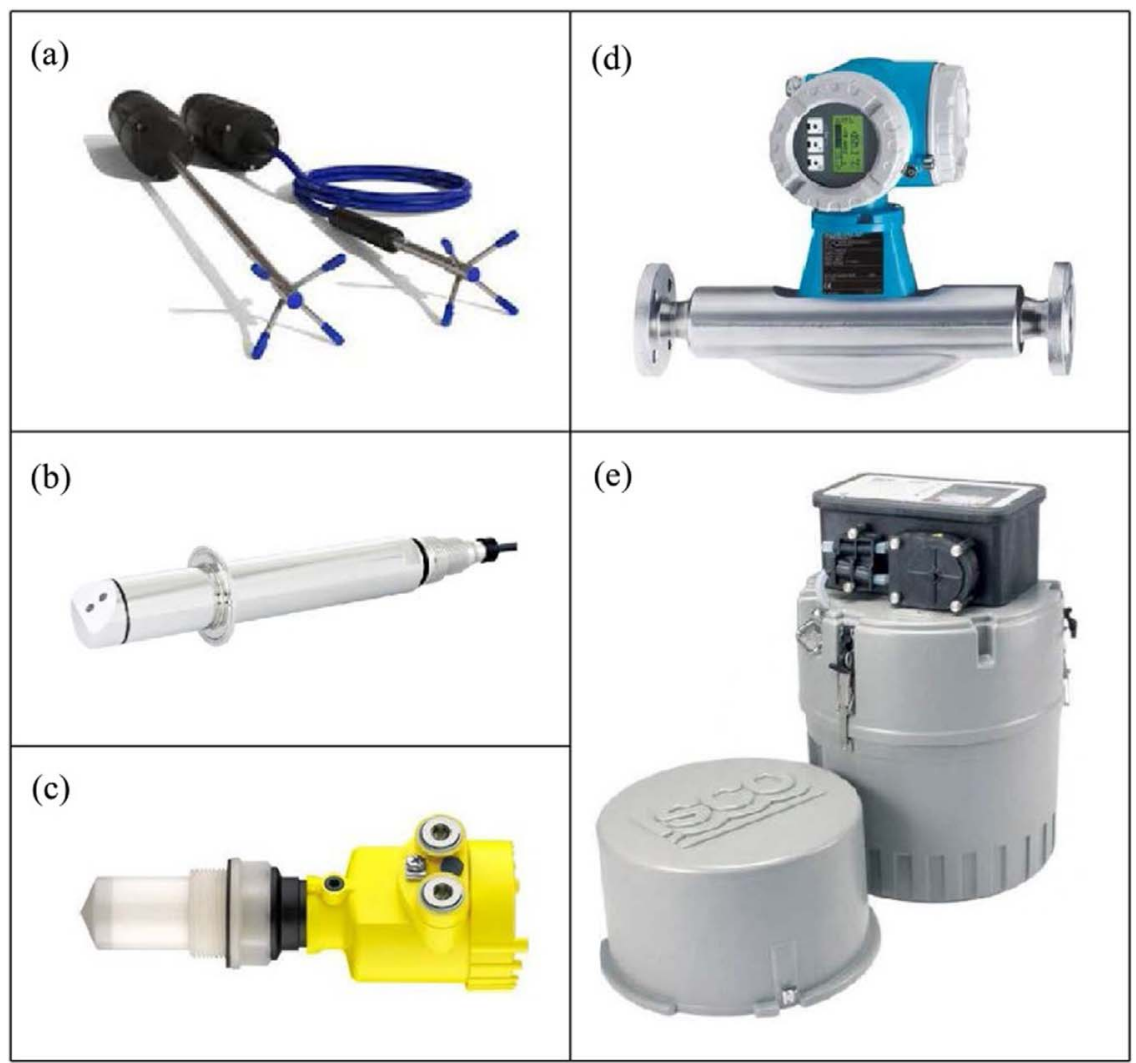

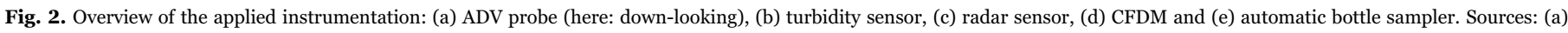
Nortek AS, (b, d) Endress+Hauser, (c) Vega, (e) Teledyne.

\subsection{Radar sensor}

To measure the water surface elevation, a radar sensor Vegapuls 61 of Vega was applied. Radar technique in general is found to be very appropriate for this purpose, since the effect of air movement and temperature change onto the measurements is negligible and the accuracy is very high [17]. Following the manufacturer information for the used radar sensor, the measurement accuracy is $\pm 2 \mathrm{~mm}$.

\subsection{Coriolis flow- and density meter}

The CFDM Promass 83F of Endress+Hauser was used for the density and temperature measurements of the water-sediment-mixture prevailing in the basins. The nominal measurement accuracy is \pm $0.5 \mathrm{~g} / \mathrm{l}$ for density, and $\pm 0.5{ }^{\circ} \mathrm{C} \pm 0.005$ times the measured temperature for the water-sediment-mixture temperature.

The device takes advantage of the Coriolis effect (cf [18].). Therefore, two parallel pipes flown through by the medium of interest are brought into oscillation, causing a phase shift whose magnitude is depending on the mass flow and hence on the density of the medium. The excitation frequency is readjusted instantaneously according to the density, and thus a direct correlation exists. To take effects of temperature into account, the temperature is also recorded.

CFDM devices (also denoted as vibrating tube technique) allow for estimating the SSC based on measured density (see e.g [19-21].). By means of laboratory and/or field investigations, these authors obtained good correlation between SSC calculated from CFDM density measurements and SSC determined by the gravimetric method of water samples. Basic requirements are (a) the exclusive use of CFDM data above the uncertainty range of the device and (b) the temperature correction to account for the temperature-dependency of the clear water density.

Ref. [20] present investigations in which a CFDM was successfully used to measure SSC up to $13 \mathrm{~g} / \mathrm{l}$. Limitations may arise at the presence of coarse particles in the water. Due to their inertia, they do not follow the oscillations (described as phase decoupling by [22]) leading to an underestimation of the mixture density.

\subsection{Automatic bottle sampler}

To automatically take water samples, the 3700 Full-Size Portable Sampler of Teledyne Isco was employed. It allows the collection of uniformly or non-uniformly timed samples into 24 polypropylene bottles with a volume of $1.0 \mathrm{l}$ each.

\section{Measurement campaign}

\subsection{Desanding facility characteristics}

The desanding facility Saas Balen on the Saaser Vispa river has an elongated inlet channel, a diversion and a slight left-hand bend located a few meters upstream of two parallel basins with different crosssectional geometry (Fig. 3). The investigated basin has a length of $L=35.00 \mathrm{~m}$, a width of $W=5.80 \mathrm{~m}$ and a constant depth of $D=4.95 \mathrm{~m}$. The bed is horizontal in longitudinal basin direction. At the basin outlet a weir impounds the flow. The total design discharge of the facility is $Q_{d} \approx 4 \mathrm{~m}^{3} / \mathrm{s}$, while the left basin design discharge is $Q_{d} \approx 2.2 \mathrm{~m}^{3} / \mathrm{s}$.

The desanding facility Wysswasser on the river of equal name has two inlet channels with a strong right-hand bend (Fig. 4). The total design discharge is $Q_{d}=10 \mathrm{~m}^{3} / \mathrm{s}$ and is equally distributed to the identical basins. They have a length of $L=32.00 \mathrm{~m}$, width of $W=4.00 \mathrm{~m}$ and a mean depth in basin axis of $D=6.52 \mathrm{~m}$. The longitudinal bed slope is $J_{s}=1 \%$. A weir impounds the flow at the basin outlet. 


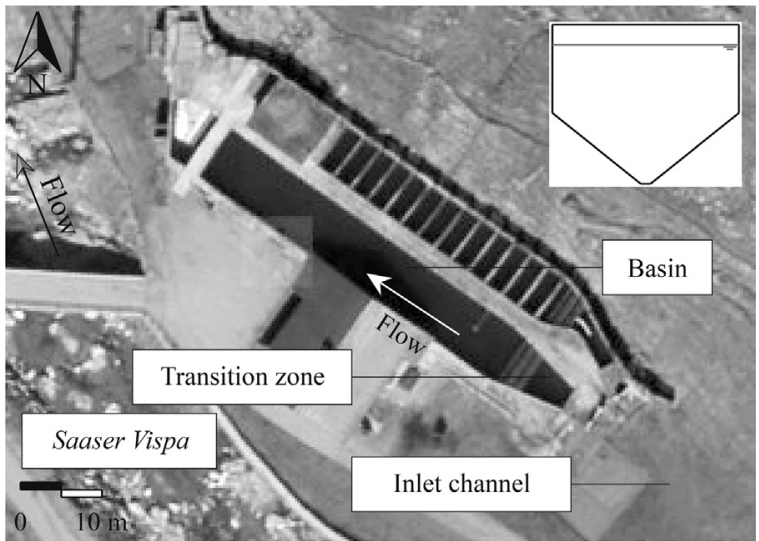

Fig. 3. Aerial picture of the desanding facility Saas Balen including schematic left basin cross section geometry. Reproduced by permission of swisstopo (JA100120).

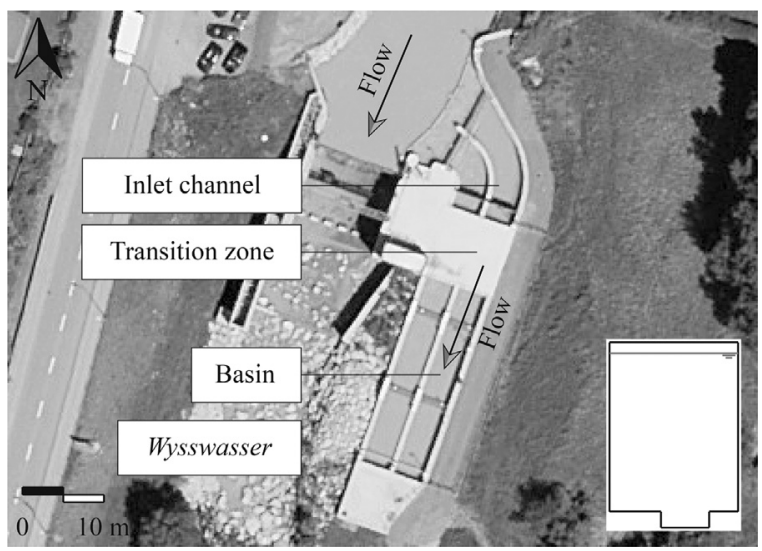

Fig. 4. Aerial picture of the desanding facility Wysswasser including schematic basin cross section geometry. Reproduced by permission of swisstopo (JA100120).

\subsection{On-site setup}

A ready-made system of freely combinable aluminum trusses of different lengths, a trolley and a motorized vertical linear unit with a stroke of $3.3 \mathrm{~m}$ have been employed. This setup was utilized as bearing structure for the ADVs and the point of water withdrawal in the basin (Figs. 5 and 6). It allowed moving the ADVs and the point of water withdrawal in the longitudinal, transverse and vertical directions of the basin, and could be easily adapted to different basin dimensions.

As shown in Fig. 5, a horizontal truss was used for measurements in transverse direction of the basin. The linear unit was vertically orientated, pointing in the direction of the basin bottom. The linear unit was attached perpendicular to the truss by means of the trolley.

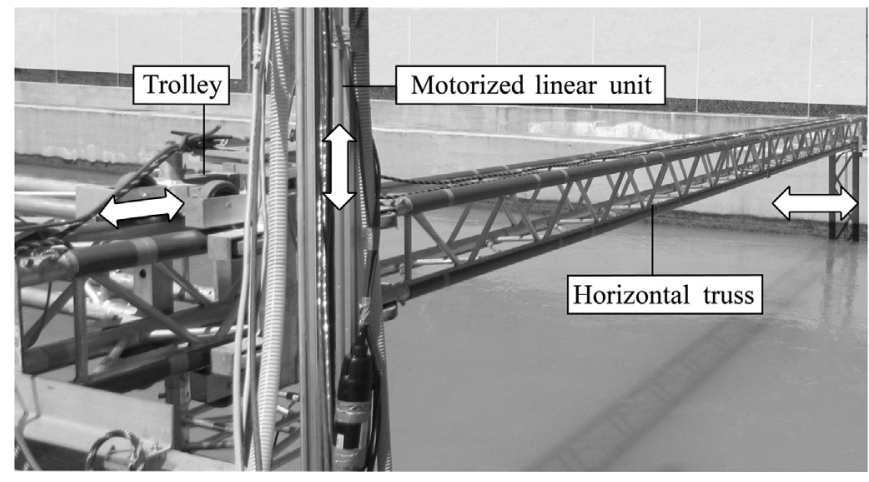

Fig. 5. On-site modular bearing system for the measurement instrumentation. Arrows indicate the directions of movement. Source: VAW.

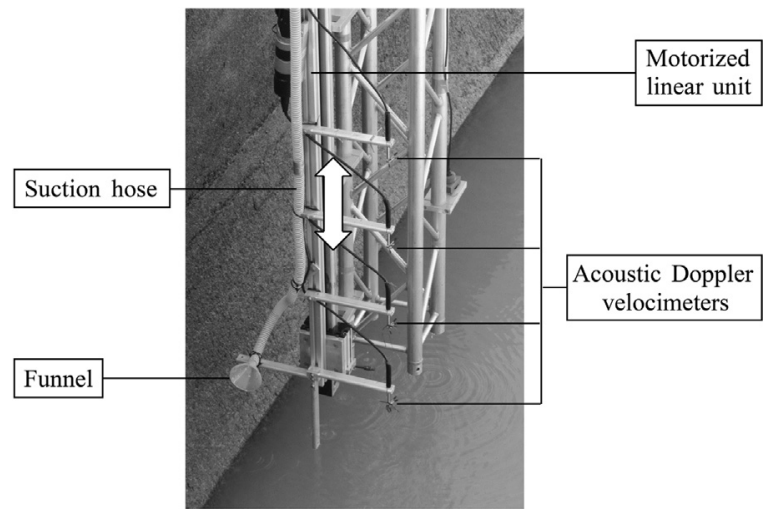

Fig. 6. Detailed view of the linear unit carrying the ADVs and the point of water withdrawal. Arrow indicates the directions of movement. Source: VAW.

Both ends of the truss were equipped with small wheels and placed on the side walls of the basin. The radar sensor was placed on the horizontal truss, thus moving with the bearing system.

Four ADVs were fixed and evenly spaced on the linear unit (Fig. 6) with a distance of $0.3 \mathrm{~m}$. The spacing and number of ADVs is virtually arbitrary. However, a cross-interference of the ADVs must be avoided. Following user experiences communicated in the Nortek knowledge center, a spacing of more than $0.1 \mathrm{~m}$ is noncritical in turbid water settings. The point of water withdrawal, represented by a funnel connected to a suction hose, was attached to the linear unit close to the lowest ADV probe.

The funnel enabled quasi-isokinetic water sampling. Its cross sectional area was adjusted at each desanding facility according to the basin mean flow velocity. At the funnel, the water was withdrawn by means of a mobile pump which was positioned next to the basin. The pump was set to a constant discharge of about $0.4 \mathrm{l} / \mathrm{s}$, ensuring that the flow velocity is sufficiently high to prevent sedimentation of particles in the suction hose.

The suction hose directed the water out of the basin and towards the CFDM and a turbidity sensor, both mounted on a mobile bearing construction. The CFDM was located after the turbidity sensor, ensuring consistent measurements of the water properties. At the end of that measuring line, water samples from 2 to 3 flow depths in each measurement cross section were manually bottled for further laboratory investigations.

Two turbidity sensors were installed at the inlet channel and at the basin outlet to continuously record the turbidity during the measurement campaign. The automatic water sampler was alternately applied at both positions. The turbidity measurement and the water withdrawal took place at mean flow depth in the middle axis at about the same point. The latter allows correlating measured turbidity and determined gravimetric SSC.

Fig. 7 shows the location of the measurement instrumentation within the desanding facilities. All data were simultaneously stored on a computer.

\subsection{Measurement routine}

At both facilities, the measurements were conducted in the orographic left basin only. In general, measurement cross sections can be realized at an arbitrary interval along the basin. The number of flow velocity measuring points in each cross section is controlled by the ADV spacing, the spacing of measurement profiles in the transverse direction, and constraints due to the maximal stroke of the linear unit. The locations of the water withdrawal are affected by the same conditions. Theoretically, there is no technical limitation for the possible measurement point density, but usually acquisition time is limited for practical reasons and temporal constraints. 


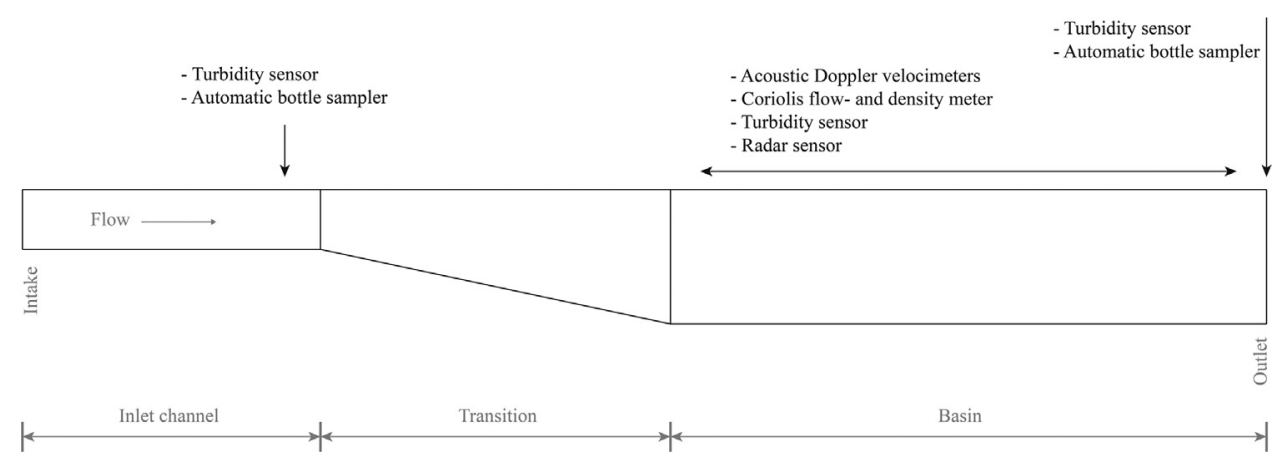

Fig. 7. Schematic illustration of location of the employed measurement instrumentation at the desanding facilities.

$$
\text { Normalized flow velocity } v_{x} / v_{i n, m}[-] \quad \begin{array}{lll}
0 & 0.19 & 0.38 \\
\end{array}
$$

(a)

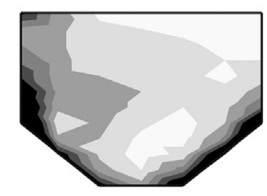

$\mathrm{x}=0$

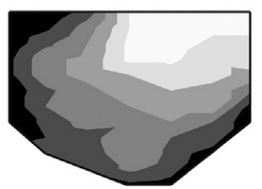

$x \approx 1 / 3 L$

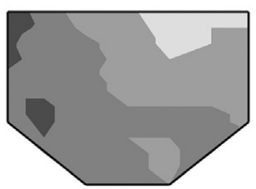

$x \approx 2 / 3 L$

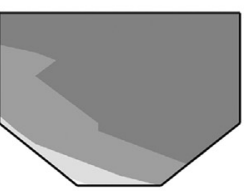

$x \approx \mathrm{L}$

(b)

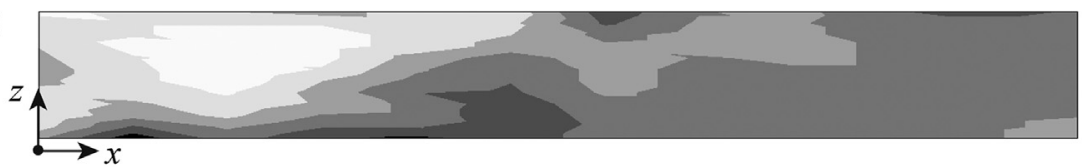

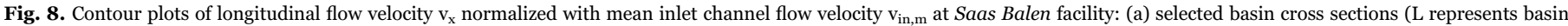
length), downstream view; (b) longitudinal section at basin centerline, flow from left to right.

$$
\text { Normalized flow velocity } v_{x} / v_{i n, m}[-] \quad \begin{array}{lll}
0 & 0.28 & 0.56 \\
\hline
\end{array}
$$

(a)

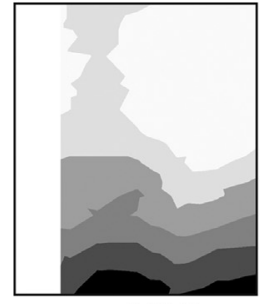

$x \approx 1 / 5 L$

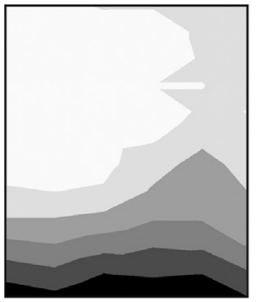

$x \approx 1 / 2 L$

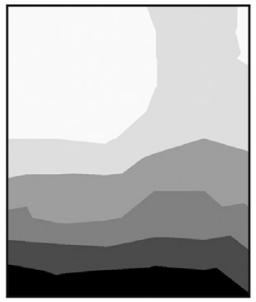

$x \approx 2 / 3 L$

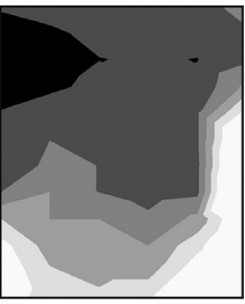

$x \approx \mathrm{L}$

(b)

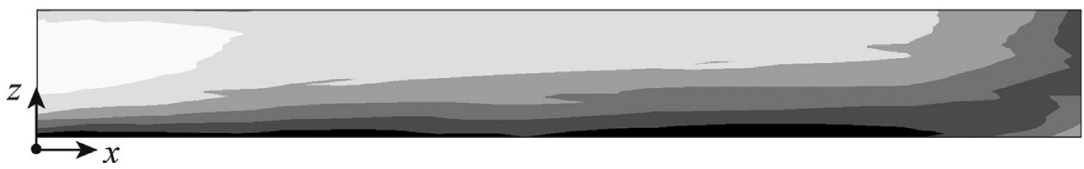

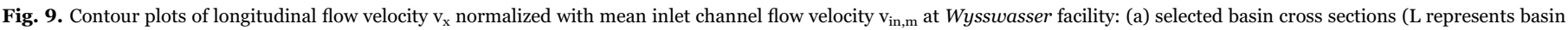
length), downstream view; (b) longitudinal section at basin centerline, flow from left to right.

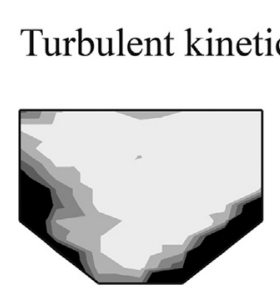

$$
\mathrm{x}=0
$$

0

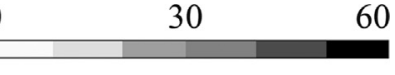

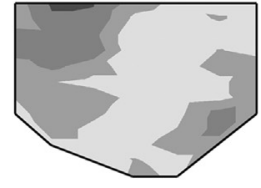

$x \approx 1 / 3 L$

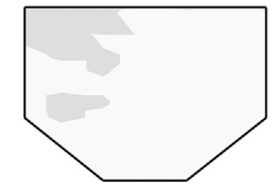

$x \approx 2 / 3 L$

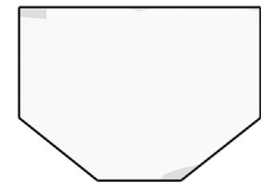

$x \approx \mathrm{L}$

Fig. 10. Contour plots of turbulent kinetic energy $e_{t, k i n}$ in selected basin cross sections at Saas Balen facility, downstream view. 


\section{Turbulent kinetic energy $e_{t, k i n}\left[\mathrm{~cm}^{2} / \mathrm{s}^{2}\right]$}

0

60

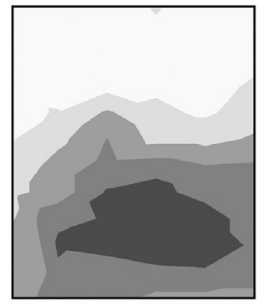

$x \approx 2 / 3 L$

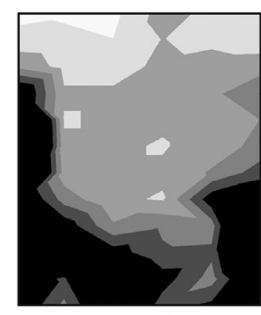

$x \approx \mathrm{L}$

Fig. 11. Contour plots of turbulent kinetic energy $e_{t, \text {,kin }}$ in selected basin cross sections at Wysswasser facility, downstream view.

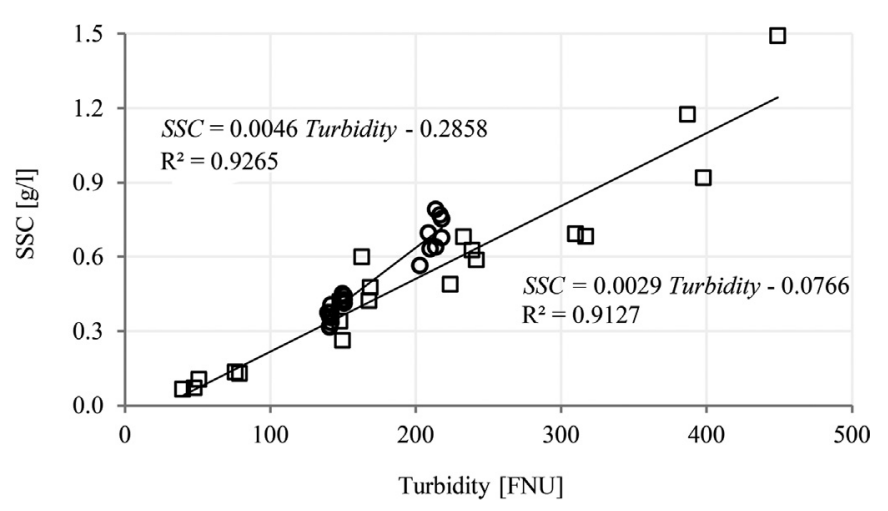

Fig. 12. Correlation of turbidity and SSC for the basin of the Saas Balen facility ( $\square$ ) and Wysswasser facility (O). The linear regressions are depicted as solid lines and $\mathrm{R}^{2}$ stands for the coefficient of determination.

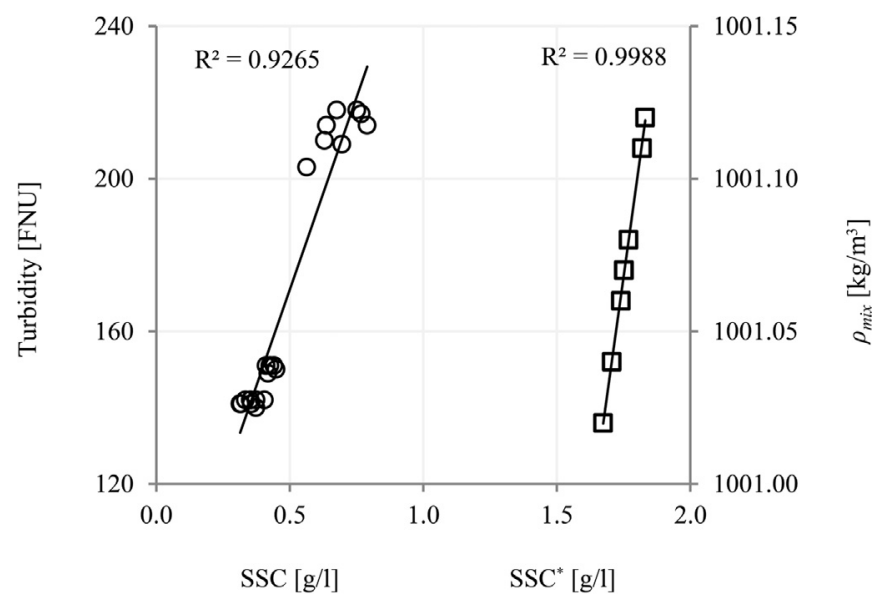

Fig. 13. Comparison of the correlation of turbidity and SSC (O), and density of the water-sediment mixture $\rho_{\text {mix }}$ (outside of the CFDM uncertainty range) and calculated $\operatorname{SSC}^{*}(\square)$, respectively, at Wysswasser facility. The linear regressions are depicted as solid lines.

Within the present field campaign, the measurement time was chosen to $90 \mathrm{~s}$ in each measuring point of the grid. The ADVs, the
CFDM, the turbidity sensor and the radar sensor sampled at a frequency of $100 \mathrm{~Hz}$. Water samples were manually taken in several flow depths along the centerline of the basin. They were stored in a refrigerator to prevent the growth of organic material such as algae.

\section{Data analysis and selected results}

The ADV raw data files were filtered based on the phase-space threshold method proposed by [23] and modified by [24] as implemented in the software WinADV.

On the one hand, the processed data are used to calculate the averaged flow velocity magnitude as well as flow direction at the measuring points to obtain an insight into the flow field within the whole basin, provided that all measurements are conducted at constant discharge conditions. For the investigated facilities, the operators provided the time series of the discharge. The discharge remained approximately constant at both facilities with maximum fluctuations in the range of $50 \mathrm{l} / \mathrm{s}$ (less than 1-2.2\% of the design discharge) during the measurement period. Examples of flow velocity contour plots are shown in Fig. 8 (Saas Balen) and Fig. 9 (Wysswasser). The plots show the basin longitudinal flow velocity component $v_{x}$ normalized with the mean flow velocity in the inlet channel $v_{i n, m}$.

On the other hand, the turbulent flow velocity fluctuations recorded with the $\mathrm{ADV}$ probes facilitate calculating turbulence intensities as well as the kinetic turbulent energy in any section of interest. Examples of the latter are presented in Fig. 10 (Saas Balen) and Fig. 11 (Wysswasser) for selected cross sections.

The measured turbidities were correlated with the determined gravimetric SSC from bottle samples (Fig. 12). A linear correlation of turbidity and SSC can be identified. Therefore, SSC can be calculated from the detected regression equation based on turbidity with acceptable reliability. Because of the presence of mainly two point clouds for the facility Wysswasser, the correlation for this case must be interpreted carefully.

In the context of evaluating the CFDM measurement data of the facility Wysswasser, it turned out that the measurements yield a valuable correlation of water-sediment mixture density $\rho_{\text {mix }}$ and determined gravimetric SSC from bottle samples solely in a certain data range. After excluding data sets with SSC values lower than $0.5 \mathrm{~g} / \mathrm{l}$ as determined based on bottle samples, the correlation presented in

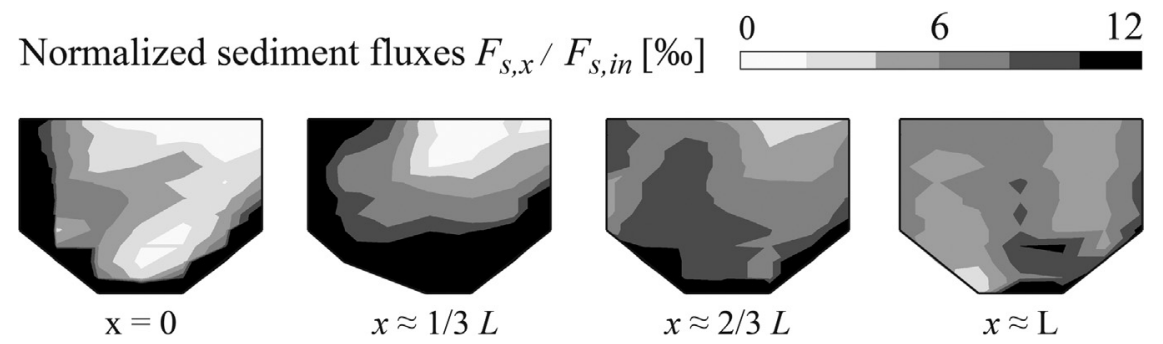

Fig. 14. Cross sectional contour plots of sediment fluxes $F_{s, x}$ normalized with instantaneous mean inlet channel sediment flux $F_{s, i n}$ at $S a a s$ Balen facility, downstream view. 


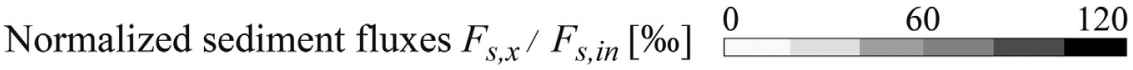

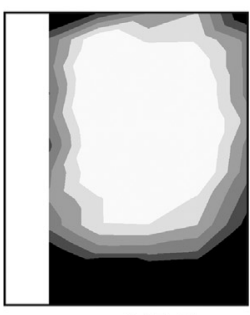

$x \approx 1 / 5 L$

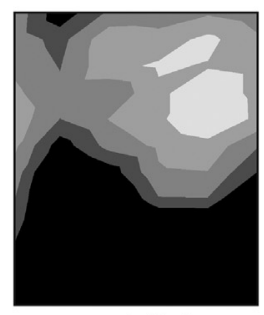

$x \approx 1 / 2 L$

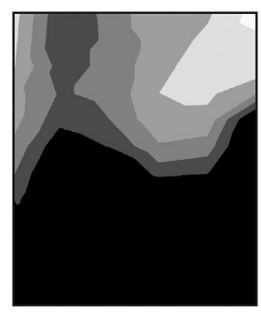

$x \approx 2 / 3 L$

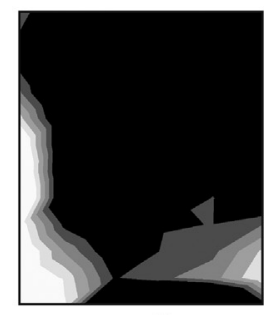

$x \approx \mathrm{L}$

Fig. 15. Cross sectional contour plots of sediment fluxes $F_{s, x}$ normalized with instantaneous mean inlet channel sediment flux $F_{s, i n}$ at $W y s s w a s s e r$ facility, downstream view.

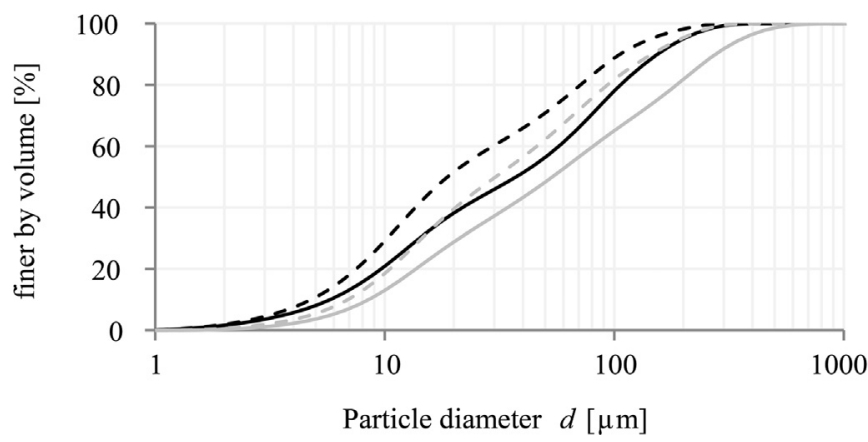

Fig. 16. Average PSD at the inlet (grey, solid line) and outlet (grey, dashed line) of Saas Balen facility and at the inlet (black, solid line) and outlet (black, dashed line) of Wysswasser facility.

Fig. 13 was obtained (correlation of turbidity and SSC additionally shown for comparison). This data treatment is reasonable, because the lower bound of the application range of the CFDM corresponds to $0.5 \mathrm{~g} / \mathrm{l}$. To obtain the calculated suspended sediment concentration values (denoted as $\mathrm{SSC}^{*}$ ) from the density measurements, the following equation is used:

$S S C^{*}=\left(\rho_{\text {mix }}-\rho_{w}\right)\left(1-\frac{\rho_{w}}{\rho_{s}}\right) \quad[\mathrm{g} / \mathrm{l}]$

where $\rho_{\boldsymbol{w}}=$ clear water density $\left[\mathrm{kg} / \mathrm{m}^{3}\right]$ and $\rho_{\boldsymbol{s}}=$ sediment solid density $\left[\mathrm{kg} / \mathrm{m}^{3}\right]$.

As can be seen from Fig. 13, a rather constant offset of roughly $1.1 \mathrm{~g} / \mathrm{l}$ between SSC from bottle samples (conceded as true) and the calculated $\mathrm{SSC}^{*}$ exists. This might be device-specific, but is not further investigated. The CFDM data from the facility Saas Balen could not be used at all due to strong data scattering. One reason for this bias might be the presence of air bubbles in the system during the measurements, which however was not further investigated.

Since reliable correlations of turbidity and SSC were found for the Wysswasser facility (see Fig. 12), CFDM data was not used further for correlation of density and SSC. The correlations of turbidity and SSC were used to estimate the sediment fluxes $F_{S}$ :

$F_{S}=\operatorname{SSC} \cdot Q \quad[\mathrm{~kg} / \mathrm{s}]$

where $Q=$ water discharge $\left[\mathrm{m}^{3} / \mathrm{s}\right]$.

Applying Eq. (2) on the partial flow areas given by the measurement grid, the cross sectional distribution of sediment fluxes can be obtained. Fig. 14 (Saas Balen) and Fig. 15 (Wysswasser) show selected cross sectional contour plots of the sediment fluxes $F_{S, x}$ normalized with the instantaneous mean inlet channel sediment flux $F_{S, \text { in }}$.

By considering the averaged sediment fluxes at the inlet channel $\left(F_{S, \text { in }}\right)$ and the basin outlet $\left(F_{S, \text { out }}\right)$, both determined based on the respective continuous turbidity measurements and the discharge records provided by the operators, the mass-related trapping efficiency $\eta$ of a desanding facility can be estimated as to:
$\eta=\left(F_{S, \text { in }}-F_{S, \text { out }}\right) / F_{S, \text { in }} \quad[-]$

For the facility Saas Balen, the sediment fluxes resulted in $F_{S, \text { in }}=1.42 \mathrm{~kg} / \mathrm{s}$ and $F_{S, \text { out }}=0.51 \mathrm{~kg} / \mathrm{s}$, respectively, giving a calculative trapping efficiency of $\eta=0.64$. For the facility Wysswasser, the sediment fluxes are $F_{S, \text { in }}=2.81 \mathrm{~kg} / \mathrm{s}$ and $F_{S, \text { out }}=1.54 \mathrm{~kg} / \mathrm{s}$, respectively, resulting in a trapping efficiency of $\eta=0.45$.

Furthermore, the determination of the averaged PSD in the inlet channel and the outlet of the facilities (see Fig. 16) shows a refinement of the median particle size. The median particle size $d_{50}$ is reduced from 54 to $30 \mu \mathrm{m}$ at Saas Balen and from 37 to $19 \mu \mathrm{m}$ at Wysswasser, respectively. The median particle size related trapping efficiencies are thus (54-30)/54=0.44 at Saas Balen and (37-19)/37=0.48 at Wysswasser, respectively. While both types of trapping efficiency are similar for Wysswasser, the mass-related trapping efficiency is considerably larger than the particle size related efficiency at Saas Balen. This may be due to a lack of velocity data close to the basin bottom, as partially in up to about $25 \%$ of the lowermost flow depths neither flow velocity data, nor sedimentological parameters could be recorded. This leads to some uncertainty regarding the estimation of sediment fluxes and to a lack of flow field information in the near-bed region.

\section{Conclusions}

Diverse measurement instrumentation was combined to a novel setup to record flow and sediment fluxes at desanding facilities. While flow velocities, turbidity, density and temperature of the water-sediment mixture were directly recorded on-site, the gravimetric suspended sediment concentration (SSC) and particle size distribution (PSD) were subsequently determined based on bottle samples.

The used acoustic Doppler velocimeters (ADVs) are well-suited for recording 3D flow velocities in desanding facilities at high spatial and temporal resolution. The present conditions in the investigated facilities and the rigid and low-vibration design of the modular truss system carrying the ADV probes allowed to use about $90 \%$ of the ADV data for further evaluation of the flow velocity and turbulence characteristics after filtering the raw data files.

Combining turbidity measurements and sound water sample analyses generally allowed for the definition of reliable relations to estimate the SSC based on turbidity. Nevertheless, limitations of this procedure appeared at conditions with very steady SSC and thus steady turbidity. This leads to a point cloud when relating SSC to turbidity, making the definition of a reliable regression impossible. Robust correlations for SSC and measured density were not found, which is most likely due to too low SSC values compared to the uncertainty range of the employed Coriolis flow- and density meter (CFDM). Furthermore, air bubbles entrained in the CFDM tubes might have biased the density measurements due to reduction of the density of the water-sediment (and air) mixture.

The designed construction composed of a ready-made system of aluminum trusses, a trolley and a motorized linear unit shows a high flexibility as well as stability and can be assembled with minor effort. 
However, the maximum realizable stroke of the motorized linear unit (i.e. $3.3 \mathrm{~m}$ ) has been found to be insufficient to cover the whole basin flow area in regions with the highest flow depths.

Although being exposed to sundry stresses such as weather conditions, transport, continuous operation and hydrodynamic forces, the employed experimental setup proved to be reliable and robust. Within a total of 6 measurement days, about $1500 \mathrm{ADV}$ and 375 single turbidity/density measurement points were realized at the two facilities. About 75 water samples and 6 deposition samples were taken.

\section{Acknowledgements}

This project is financially supported by the Swiss National Science Foundation (NRP70, No. 153861) and technically supported by EnAlpin (HPP Ackersand I), Gommerkraftwerke AG (HPP Wysswasser) and Swiss Federal Railways (HPP Massaboden). It is under the umbrella of the Swiss Competence Center of Energy Research - Supply of Energy (SCCER-SoE).

\section{References}

[1] M.K. Padhy, R.P. Saini, Study of silt erosion on performance of a Pelton turbine, Energy 36 (1) (2011) 141-147.

[2] C. Ortmanns, Entsander von Wasserkraftanlagen ('Desanding Facilities at Hydroelectric Power Plants'), VAW-Mitteilung 193, VAW, ETH Zurich, Zurich, 2006 (in German).

[3] E. Mosonyi, Water Power Development, Publishing House of the Hungarian Academy of Sciences, Budapest, Hungary, 1956.

[4] J. Giesecke, S. Heimerl, E. Mosonyi, Wasserkraftanlagen - Planung, Bau und Betrieb ('Hydroelectric Power Plants - Planning, Construction and Operation'), Springer, Berlin, 2014 (in German).

[5] N.C. Kraus, A. Lohrmann, R. Cabrera, New acoustic meter for measuring 3D laboratory flows, J. Hydraul. Eng. 120 (3) (1994) 406-411.

[6] H. Chanson, Acoustic Doppler velocimetry (ADV) in the field and in laboratory: practical experiences, in: F.L. Larrarte, H. Chanson (eds.), International Meeting on Measurements and Hydraulics of Sewers IMMHS'08, Summer School GEMCEA/ LCPC, 49-66, Department of Civil Engineering at The University of Queensland, 2008.

[7] G. Voulgaris, J.H. Trowbridge, Evaluation of the acoustic Doppler Velocimeter (ADV) for turbulence measurements, J. Atmos. Ocean. Technol. 15 (1) (1998) 272-289.

[8] A. Lohrmann, R. Cabrera, N.C. Kraus, Acoustic-Doppler velocimeter (ADV) for laboratory use, in: Fundamentals and Advancements in Hydraulic Measurements and Experimentation, 351-365, ASCE, 1994.

[9] C.M. García, M.I. Cantero, Y. Niño, M. García, Turbulence measurements with acoustic Doppler velocimeters, J. Hydraul. Eng. 131 (12) (2005) 1062-1073.

[10] P.J. Rusello, A. Lohrmann, E. Siegel, T. Maddux, Improvements in acoustic Doppler velocimetry, 7th International Conference on Hydroscience and Engineering, 2006.

[11] G.H. Merten, P.D. Capel, J.P.G. Minella, Effects of suspended sediment concentration and grain size on three optical turbidity sensors, J. Soils Sediment. 14 (7) (2013) 1235-1241.

[12] R.M. Boes, Real-time monitoring of suspended sediment concentration and particle size distribution in the headwater way of a high-head hydropower plant, Proceedings 33rd IAHR Congress, Vancouver, 11026, 4037-4044, 2009.

[13] R.M. Boes, D. Felix, I. Albayrak, Schwebstoffmonitoring zum verschleissoptimierten Betrieb von Hochdruck-Wasserkraftanlagen ('Monitoring suspended sediments fort he wear-optimized operation of high-head hydroelectric power plans'), Wasser Energ. Luft. 105 (1) (2013) 35-42 (in German).

[14] D.G. Wren, B.D. Barkdoll, R.A. Kuhnle, R.W. Derrow, Field techniques for suspended-sediment-measurement, J. Hydraul. Eng. 126 (2) (2000) 97-104.

[15] D. Felix, I. Albayrak, R.M. Boes, Schwebstoffmonitoring und Verschleiss an Peltonturbinen am Fallbeispiel Fieschertal - Vorbereitende Laborversuche zu Partikel-messmethoden ('Suspended sediment monitoring and wear of Pelton turbines at the field study Fieschertal - Preliminary laboratory tests regarding particle measurement method'), in: G. Zenz (ed.), Proceedings Wasserbausymposium, 2012, 117-124, (in German).

[16] C.S. Conner, A.M. DeVisser, A laboratory investigation of particle size effects on an optical backscatterance sensor, Mar. Geol. 108 (2) (1992) 151-159.

[17] J.M. Fulford, L.W. Ester, J.W. Heaton, Accuracy of radar water level measurements, in: Hydraulic Measurements and Experimental Methods Conference, Lake Placid/USA, 2007.

[18] P. Kalotay, Density and viscosity monitoring systems using Coriolis flow meters, ISA Trans. 38 (4) (1999) 303-310.

[19] M.B. Bishwakarma, H. Støle, Real-time sediment monitoring in hydropower plants, J. Hydraul. Res. 46 (2) (2008) 282-288.

[20] D. Felix, I. Albayrak, R.M. Boes, Combining in-situ laser diffraction (LISST) and vibrating tube densimetry to measure low and high suspended sediment concentrations, Proc. 13th International Symposium on River Sedimentation: 1264-1271, 2016.

[21] J.N. Fernandes, R.M. Boes, M. Titzschkau, A. Hammer, S. Haun, M. Schletterer, Suspended sediment concentrations and turbine wear during the drawdown of two Alpine reservoirs, Proceedings Hydro 2016 Conference, Montreux, Switzerland: Paper 235, 2016.

[22] N.T. Basse, A review of the theory of Coriolis flowmeter measurement errors due to entrained particles, Flow Meas. Instrum. 37 (2014) 107-118.

[23] D.G. Goring, V.I. Nikora, Despiking acoustic Doppler velocimeter data, J. Hydraul. Eng. 128 (1) (2002) 117-126.

[24] T.L. Wahl, Discussion of 'Despiking acoustic Doppler velocimeter data' by Derek G. Goring and Vladimir I. Nikora, J. Hydraul. Eng. 129 (6) (2003) 484-487. 